\title{
Alterações anatômicas do sistema vascular em porta-enxertos de videira
}

\author{
Emiliano Santarosa(1), Paulo Vitor Dutra de Souza(2), Jorge Ernesto de Araújo Mariath(3) e Gil Vicente Lourosa ${ }^{(2)}$
}

\begin{abstract}
(1)EmbrapaFlorestas, EstradadaRibeira,Km111, CaixaPostal319, CEP83411-000Colombo,PR, Brasil.E-mail:emiliano.santarosa@embrapa.br (2)Universidade Federal do Rio Grande do Sul (UFRGS), Departamento de Horticultura e Silvicultura, Avenida Bento Gonçalves, no 7.712, CEP 91501-970 Porto Alegre, RS, Brasil. E-mail: pvdsouza@ufrgs.br, gillourosa@hotmail.com (3)UFRGS, Departamento de Botânica, Avenida Bento Gonçalves, no 7.712, CEP 91501-970 Porto Alegre, RS, Brasil. E-mail: jorge.mariath@ufrgs.br
\end{abstract}

Resumo - O objetivo deste trabalho foi avaliar a ocorrência de alterações do padrão de vascularização de porta-enxertos de videira. Utilizaram-se os genótipos Paulsen 1103 (Vitis berlandieri $\mathrm{x}$ Vitis rupestris), MGT 101-14 (Vitis riparia $\times$ V. rupestris) e SO4 (V. berlandieri x V. riparia). O experimento foi conduzido em delineamento de blocos ao acaso com três tratamentos (genótipos) e dez plantas por parcela. Avaliaram-se as variáveis de crescimento vegetativo dos porta-enxertos e, por meio de cortes histológicos realizados no ápice, na porção mediana e na base dos ramos, as anatômicas. As diferenças no sistema vascular tornaram-se maiores do ápice para a base dos ramos. Os genótipos SO4 e Paulsen 1103 apresentaram maior área de xilema na base dos ramos, 2,61 e 2,51 mm², respectivamente, e maior diâmetro dos vasos, 45,8 e 47,2 $\mu \mathrm{m}$, respectivamente, em comparação ao MGT 101-14 que apresentou 1,60 $\mathrm{mm}^{2}$ de xilema e 34,1 $\mu \mathrm{m}$ de diâmetro dos vasos. Ocorreram modificações também na frequência dos vasos. A área de xilema, o diâmetro e a frequência dos vasos estão relacionados ao crescimento vegetativo dos porta-enxertos. As alterações do padrão de vascularização podem ser um critério para a escolha de porta-enxertos, em razão de sua influência sobre os processos fisiológicos.

Termos para indexação: Vitis, fisiologia, padrão de vascularização, videiras, xilema.

\section{Anatomic changes of the vascular system in grapevine rootstocks}

\begin{abstract}
The objective of this work was to evaluate the occurrence of changes in the vascularization pattern of grapevine rootstocks. The genotypes Paulsen 1103 (Vitis berlandieri x Vitis rupestris), 101-14 MGT (Vitis riparia $\mathrm{x}$ V. rupestris), and SO4 ( $V$. berlandieri $\mathrm{x}$ V. riparia) were used. The experiment was carried out in a randomized complete block design with three treatments (genotypes) and ten plants per plot. Vegetative growth of grapevine rootstocks and anatomic variables, by the analysis of histological sections performed in the apex, middle, and base portion of the stem, were evaluated. The differences in the vascular system became larger from the apex to the base. The SO4 and Paulsen 1103 genotypes had higher xylem area in the base of the stem, of 2.61 and $2.51 \mathrm{~mm}^{2}$, respectively, and larger diameter of vessels, of 45.8 and $47.2 \mu \mathrm{m}$, respectively, in comparison to 101-14 MGT that showed $1.60 \mathrm{~mm}^{2}$ for xylem and $34.1 \mu \mathrm{m}$ for vessel diameter. Modifications also occurred for the frequency of vessels. The xylem area, diameter, and frequency of vessels are related to rootstock vegetative growth. Vascularization pattern changes may be a criterion for the choice of rootstocks, due to their effect on the physiological processes.
\end{abstract}

Index terms: Vitis, physiology, vascularization pattern, grapevines, xylem.

\section{Introdução}

A escolha do porta-enxerto de videira fundamenta-se em características como resistência a pragas e doenças, características do solo (calcários, ácidos, salinos), variedade de videira a ser cultivada e condições de cultivo (Miele et al., 2009). Além destas características, sabe-se que os porta-enxertos, em geral, influenciam de forma diferente o vigor e o desenvolvimento da variedade copa, fator que também é determinante para sua escolha conforme o objetivo da produção. Porém, são poucos os estudos sobre a interação porta-enxerto/ copa que apresentem os fatores fisiológicos determinantes dessas diferenças, aos quais o padrão de vascularização pode estar relacionado.

O xilema e o floema são os principais tecidos que formam o sistema vascular, cujo crescimento secundário depende da diferenciação do câmbio vascular (Lucas et al., 2013; Santarosa et al., 2016). A atividade do câmbio vascular apresenta relação com o balanço hormonal, pois, alguns hormônios apresentam funções como a diferenciação e a formação de novos 
tecidos (Aloni et al., 2010). Modificações do sistema vascular ocorrem em diferentes espécies frutíferas (Olmstead et al., 2006; Rodríguez-Gamir et al., 2010; Tombesi et al., 2010), com influências sobre a formação dos frutos (Choat et al., 2009) e a incidência de doenças (Thorne et al., 2006; Chatelet et al., 2011). Estas alterações afetam processos fisiológicos como a resistência hidráulica e a suscetibilidade ao embolismo (Brodersen et al., 2010; Lucas et al., 2013). Em plantas superiores, os tecidos vasculares desempenham papéis essenciais em outros processos além da fisiologia do transporte de água e nutrientes, pois atuam também no desenvolvimento (transferência de moléculas de sinalização) e na arquitetura da planta, por meio do suporte físico (Jung et al., 2007). Por isso, as alterações do padrão de vascularização, nos porta-enxertos de videira, consistem em características importantes que devem ser avaliadas na escolha do genótipo, para que este seja adequado a cada situação de cultivo.

Nos porta-enxertos, possíveis modificações do sistema vascular podem apresentar influência na interação porta-enxerto/copa (Martínez-Ballesta et al., 2010; Santarosa et al., 2016), e estas interações alteram o vigor e a produção em regiões de deficit hídricos (Pavlousek, 2011; Keller et al., 2012) e modificam as relações hídricas (Pire et al., 2010; Alsina et al., 2011). Entretanto, são poucos os estudos sobre os genótipos de porta-enxertos de videira especificamente relacionados ao padrão de vascularização.

A análise do sistema vascular dos porta-enxertos pode também mostrar as alterações fisiológicas oriundas da enxertia, como as alterações no crescimento vegetativo, bem como auxiliar o entendimento das características anatômicas de cada genótipo.

O objetivo deste trabalho foi avaliar a ocorrência de alterações do padrão de vascularização de porta-enxertos de videira.

\section{Material e Métodos}

O experimento foi realizado no período de crescimento vegetativo 2009-2010, em casa de vegetação, do Departamento de Horticultura e Silvicultura, Universidade Federal do Rio Grande do Sul, em Porto Alegre, RS, Brasil. Foram avaliados o desenvolvimento vegetativo e o sistema vascular dos porta-enxertos Paulsen 1103 (Vitis berlandieri x Vitis rupestris), MGT 101-14 (Vitis riparia $\mathrm{x}$ V. rupestris) e $\mathrm{SO} 4$ ( $V$. berlandieri x $V$. riparia). Utilizou-se o delineamento experimental de blocos ao acaso, com três tratamentos, quatro repetições e com 10 plantas por parcela.

Em 2009, na época de repouso vegetativo, coletaram-se ramos para a preparação de estacas, para o enraizamento dos porta-enxertos. Estacas de 1 a $1,5 \mathrm{~cm}$ de diâmetro e $30 \mathrm{~cm}$ de comprimento, que continham quatro gemas, foram preparadas, colocadas no leito de enraizamento, constituído de substrato areia, e acondicionadas em casa de vegetação com sistema de nebulização intermitente. Após o enraizamento, as estacas foram acondicionadas em recipientes de $5 \mathrm{~L}$ (uma planta por vaso), com substrato composto por casca de pinus, vermiculita expandida e carvão moído, com $\mathrm{pH} 5,8$, condutividade elétrica de $1,7 \mathrm{mS} \mathrm{cm}^{-1}$, densidade de $274,6 \mathrm{~kg} \mathrm{~m}^{-3}$, capacidade de retenção de água de $55 \%$ e humidade máxima de $50 \%$. As mudas foram conduzidas em haste única, e a irrigação foi realizada com disponibilidade hídrica próxima à de capacidade de campo (recipiente), com regas diárias. O manejo fitossanitário foi realizado de acordo com recomendações para cultura da videira, e as mudas foram conduzidas em luz natural, na casa de vegetação, em que a temperatura média foi de $20,1^{\circ} \mathrm{C}$, a umidade relativa foi de $80,3 \%$, e as temperaturas médias mínima e máxima foram de 16,6 e $26,9^{\circ} \mathrm{C}$, respectivamente.

Após 160 dias da brotação, as plantas foram avaliadas quanto ao crescimento vegetativo, tendo-se mensurado: a massa de matéria fresca (MF) e a massa de matéria seca das folhas (MS), dos ramos, do caule ou estaca e das raízes. A massa de matéria seca foi determinada por meio da coleta de folhas, ramos, caule (estaca) e raízes, que foram acondicionados em sacos de papel com identificação e levados ao laboratório, onde foram pesados para obtenção da MF e, posteriormente, foram colocados para secar a $65^{\circ} \mathrm{C}$ em estufa com circulação forçada de ar, até atingirem a estabilização da MS. A massa de matéria seca foi aferida em balança de precisão. Avaliaram-se, também: a área foliar utilizando o medidor modelo 3100 (LI-Cor, Lincoln, Nebraska USA), o número de folhas, o número de nós e o número de raízes (no momento do transplante).

As análises anatômicas foram realizadas no Laboratório de Anatomia Vegetal, do Departamento de Botânica, Instituto de Biociências, Universidade Federal do Rio Grande do Sul. Após 160 dias de crescimento vegetativo, coletaram-se os segmentos dos 
ramos com $20 \mathrm{~mm}$ de comprimento, na porção basal, mediana e apical de cada ramo. Na parte basal dos ramos, realizou-se a coleta no segundo entrenó e, nas demais partes, de acordo com o comprimento total do ramo. Após a propagação por estaquia, coletaram-se os segmentos dos ramos dos porta-enxertos provenientes do primeiro período de crescimento vegetativo. De forma aleatória, colheram-se oito plantas por tratamento, para a análise anatômica.

Para a análise anatômica, as amostras dos ramos foram fixadas em solução de glutaraldeído a $1 \%$, formaldeído a 4\%, em tampão fosfato, $\mathrm{pH} 7,2$, $0,1 \mathrm{~mol} \mathrm{~L}^{-1}$ e conservadas em frascos de vidro de $50 \mathrm{~mL}$. As amostras foram colocadas em aparelho a vácuo, durante 48 horas, para a retirada de ar de todos os tecidos e fixação adequada do material. Os segmentos com maior diâmetro foram seccionados em micrótomo de deslize, tendo-se obtido secções de 15 a $25 \mu \mathrm{m}$ de espessuras. Das amostras com menor diâmetro, obtiveram-se seções à mão livre ou com micrótomo de Ranvier, por meio de navalha específica. As seções obtidas foram coradas com azul de astra $(1 \%)+$ safranina $(1 \%)$, conforme metodologia de O’Brien \& McCully (1981), para posterior análise microscópica conforme Gerlach (1977). A composição do corante foi a seguinte: gelatina, $5 \mathrm{~g}$; água, $30 \mathrm{~mL}$; glicerina, $35 \mathrm{~mL}$; fenol, 5 gotas ou 1 cristal; corantes azul de astra a $1 \%$ e safranina a $1 \%$.

Em cada seção transversal de lenho, realizaram-se fotomicrografias em microscópio Leica DMR-HC, com câmera digital Leica DC500 acoplada ao microscópio. As contagens e medições foram realizadas com o auxílio de programa de análise e processamento de imagens Image J (Schneider et al., 2012). Por meio da seção transversal do lenho, quantificaram-se diferentes variáveis anatômicas como área de xilema, medula, floema (floema primário e secundário), perímetro dos ramos e relação xilema/floema para as porções apical, mediana e basal dos ramos. Em cada corte transversal, realizaram-se quantificações da área total dos tecidos do sistema vascular, enquanto que as variáveis como diâmetro, área, densidade, número total, frequência e distribuição dos elementos de vaso foram mensuradas em quatro porções delimitadas do xilema, que corresponderam às áreas delimitadas por raios parenquimáticos, em posições de $90^{\circ}$ uma em relação à outra (Lovisolo et al., 2002). Como adaptação do método, optou-se por aumentar a área amostral e incluir como unidade amostral a zona compreendida entre três raios parenquimáticos, em cada uma das quatro porções do corte transversal. De cada planta, foram obtidas três imagens gerais (ápice, mediana e base do ramo) e, em cada corte, mais quatro imagens detalhadas para a análise dos vasos, o que resultou em 15 imagens processadas por planta.

Os dados foram submetidos à análise de variância, e as médias foram submetidas ao teste de comparações múltiplas, pelo teste de Tukey, a 5\% de probabilidade. A análise estatística foi executada com o programa SAS - Statistical Analysis System (SAS Institute, Cary, NC, EUA).

\section{Resultados e Discussão}

Os porta-enxertos de videira apresentaram diferenças de crescimento vegetativo, evidenciados principalmente pelo conteúdo de massa de matéria fresca (MF) e massa de matéria seca (MS) das folhas, ramos e sistema radicular. Os porta-enxertos Paulsen 1103 e SO4 apresentaram semelhanças quanto à MF, ramos e raízes, tendo sido superiores ao porta-enxerto MGT 101-14 (Tabela 1). O porta-enxerto MGT 101-14 apresentou o menor conteúdo de massa de matéria seca (MS) das folhas e a menor área foliar. Além disso, em comparação ao MGT 101-14, o porta-enxerto SO4 apresentou o maior conteúdo de MS do ramo, mas sem diferir do Paulsen 1103. Quanto ao conteúdo do sistema radicular, Paulsen 1103 apresentou o maior valor, diferiu do MGT 101-14 e foi similar ao SO4. O porta-enxerto MGT 101-14 apresentou menor crescimento vegetativo do que o Paulsen 1103 e o SO4, possivelmente relacionado às diferenças de morfologia e desenvolvimento do sistema radicular, tendo, consequentemente, influenciado o desenvolvimento da parte aérea, o que pode ser um critério de seleção dos porta-enxertos.

Resultados de outros experimentos com videiras são indicativos de que modificações da copa ocorrem em consequência de diferenças de vigor dos porta-enxertos (Koundouras et al., 2008), assim como em citros (Rodríguez-Gamir et al., 2010) e pereiras (Solari et al., 2006). Outros estudos também apontam a diferença de crescimento vegetativo como característica relacionada ao vigor dos porta-enxertos em macieiras (Cohen et al., 2007) e cerejeiras (Gonçalves et al., 2007).

Houve aumento da área de xilema secundário, ao longo do ramo, de acordo com o crescimento e aumento do ramo em diâmetro (Figura 1). No ápice 
da planta, foi possível observar diferença significativa entre os porta-enxertos. À medida que ocorreu o crescimento secundário do xilema, as diferenças entre os porta-enxertos tornaram-se maiores, e os genótipos SO4 e Paulsen 1103 foram os que apresentaram maior área de xilema na base do ramo - respectivamente, 2,61 e 2,51 $\mathrm{mm}^{2}$-, em comparação ao porta-enxerto MGT 101-14, que apresentou em média $1,60 \mathrm{~mm}^{2}$. A maior área de xilema está relacionada ao maior vigor dos porta-enxertos, ou seja, quanto maior o crescimento vegetativo, maior a área de xilema, que é a estrutura do sistema vascular mais influenciada pela taxa de diferenciação dos tecidos nos meristemas apicais e câmbio vascular. Estas características do tecido xilemático podem estar relacionadas à maior ou menor resistência hidráulica da planta e às características dos elementos de vaso do xilema (Olmstead, 2006; Wu et al., 2011). Outros trabalhos também têm mostrado a formação das estruturas do sistema vascular em relação ao vigor dos porta-enxertos (Cohen et al., 2007; Gonçalves et al., 2007). A condutividade hidráulica do xilema é um dos fatores relacionados ao vigor (Solari et al., 2006; Solari \& DeJong, 2006; Tombesi et al., 2010), pois, a capacidade de uma planta de absorver e transportar água e nutrientes também depende das estruturas anatômicas (Wu et al., 2011; Lucas et al., 2013). Estas afirmações são reforçadas também por Rodríguez-Gamir et al. (2010), que relataram relação positiva entre condutividade hidráulica e a biomassa foliar.

Não houve diferença significativa entre os porta-enxertos quanto à área de medula e para área de floema (Figura 2), esta última é responsável pelo transporte de carboidratos, aminoácidos e outros compostos orgânicos (Lucas et al., 2013). Ocorreu aumento da área de floema e da medula, em razão do crescimento secundário, de acordo com a diferenciação do câmbio vascular e crescimento do ramo, mas sem diferença entre os porta-enxertos. Verificou-se, por meio desses resultados, que o principal componente do sistema vascular relacionado ao vigor foi o tecido do xilema, responsável pelo transporte de água e nutrientes. O índice de relação xilema/floema diferiu significativamente entre os porta-enxertos apenas no ápice, onde se observou que o porta-enxerto MGT 101-14 apresentou o menor índice, ou seja, apresentou menor área de xilema proporcionalmente à área de floema. Ocorreu pouca variação em relação à porção apical, mediana e basal do ramo. Também não houve diferenças significativas nos perímetros dos ramos dos porta-enxertos, em que se observou apenas um incremento do perímetro, ao longo do crescimento secundário, nas diferentes porções dos ramos, sem haver diferença significativa entre os tratamentos.

Os porta-enxertos apresentaram alterações de diâmetro médio e área dos elementos de vaso, que são estruturas do sistema vascular com relação direta com a resistência hidráulica. Ocorreram diferenças significativas de diâmetro (Figura 3) e da área dos elementos de vaso, em que os porta-enxertos $\mathrm{SO} 4$ e Paulsen 1103 apresentaram os maiores valores. Ao longo do crescimento secundário, ocorreu aumento das diferenças entre os porta-enxertos em relação a estas variáveis. O porta-enxerto MGT 101-14 apresentou o menor diâmetro médio dos vasos, nas diversas posições do ramo, o que indica que o vigor dos porta-enxertos está relacionado ao diâmetro dos vasos, similarmente ao encontrado em outras espécies frutíferas (Gonçalves et al., 2007; Tombesi et al., 2010). Quanto ao diâmetro dos elementos de vasos, também ocorreu aumento do diâmetro, de acordo com a posição de amostragem no ramo, com elementos de vaso maiores na porção

Tabela 1. Conteúdo médio de massa de matéria fresca (MF) e de matéria seca (MS) das folhas, dos ramos, das estacas e das raízes, área foliar, número de folhas, número de nós e número de raízes por planta de diferentes porta-enxertos de videira (Vitis spp.) $)^{(1)}$.

\begin{tabular}{|c|c|c|c|c|c|c|c|c|c|c|c|c|}
\hline \multirow[t]{2}{*}{ Porta-enxerto } & \multicolumn{4}{|c|}{ Matéria fresca (g por planta) } & \multicolumn{4}{|c|}{ Matéria seca (g por planta) } & \multirow{2}{*}{$\begin{array}{l}\text { Área foliar } \\
\left(\mathrm{cm}^{2}\right)\end{array}$} & \multirow{2}{*}{$\begin{array}{l}\text { Folhas } \\
\text { por planta }\end{array}$} & \multirow{2}{*}{$\begin{array}{c}\text { Nós por } \\
\text { planta }\end{array}$} & \multirow{2}{*}{$\begin{array}{c}\text { Raízes por } \\
\text { planta }^{(2)}\end{array}$} \\
\hline & Folhas & Ramos & Estacas & Raízes & Folhas & Ramos & Estacas & Raízes & & & & \\
\hline Paulsen 1103 & $1,52 \mathrm{a}$ & $0,36 \mathrm{a}$ & $9,72^{\mathrm{ns}}$ & $2,88 \mathrm{a}$ & $0,292 a$ & $0,124 a b$ & $4,91^{\mathrm{ns}}$ & $0,588 \mathrm{a}$ & $115,5 \mathrm{a}$ & $6,4^{\mathrm{ns}}$ & $9,3^{\text {ns }}$ & $6,9^{\text {ns }}$ \\
\hline MGT 101-14 & $1,16 b$ & $0,25 \mathrm{~b}$ & 8,42 & $1,55 b$ & $0,226 b$ & $0,095 \mathrm{~b}$ & 4,32 & $0,334 \mathrm{~b}$ & $89,5 b$ & 5,5 & 7,8 & 5,9 \\
\hline $\mathrm{SO} 4$ & $1,59 \mathrm{a}$ & $0,42 \mathrm{a}$ & 11,41 & $2,75 \mathrm{a}$ & $0,289 \mathrm{a}$ & $0,158 \mathrm{a}$ & 5,59 & $0,516 \mathrm{ab}$ & $120,7 \mathrm{a}$ & 6,0 & 9,6 & 8,1 \\
\hline $\mathrm{CV}(\%)$ & 8,6 & 15,4 & 14,0 & 20,2 & 8,02 & 22,4 & 15,3 & 21,4 & 5,9 & 18,2 & 10,5 & 24,7 \\
\hline
\end{tabular}

${ }^{(1)}$ Médias seguidas por letras iguais, nas colunas, não diferem entre si, pelo teste de Tukey, a $5 \%$ de probabilidade. ${ }^{\text {ns} N a ̃ o ~ s i g n i f i c a t i v o . ~}{ }^{(2)}$ Equivalente ao momento de transplante das mudas. $\mathrm{n}=120$. 
basal, em relação às porções mediana e apical. $\mathrm{Ou}$ seja, à medida que ocorreu o crescimento secundário do ramo, ocorreu aumento da área do xilema e do diâmetro médio dos vasos.

Estas características dos vasos estão relacionadas ao potencial de condutividade hidráulica e fluxo de seiva, em razão de sua influência sobre a resistência hidráulica (Cohen et al., 2007; Brodersen et al., 2010), quando se consideram as condições de demanda por evapotranspiração, abertura estomática e diferença de pressão ou potencial hídrico. Com os resultados, pode-se inferir que os porta-enxertos de videira mais vigorosos apresentam maior área de xilema e maior diâmetro dos elementos de vaso, ou seja, proporcionam modificações de estrutura anatômica que podem resultar em maior potencial de condutividade hidráulica, conforme verificado em outras espécies (Olmstead et al., 2006; Tombesi et al., 2010).

Verificou-se, também, maior número de vasos dos porta-enxertos Paulsen 1103 e SO4 no ápice do ramo, em comparação ao MGT 101-14 (Figura 3). Na base dos ramos, observou-se a superioridade do número total de vasos do porta-enxerto SO4. Entretanto, na posição mediana dos ramos, não ocorreram diferenças significativas entre os tratamentos. Estes resultados podem ser atribuídos à maior variabilidade dos dados quanto à variável número de vasos, na porção mediana, em relação às porções apical e basal, o que resultou na similaridade estatística entre os tratamentos, pela análise de variância. Os porta-enxertos Paulsen 1103 e MGT 101-14 apresentaram diferenças quanto ao desenvolvimento vegetativo, mas não apresentaram diferenças quanto ao número total de vasos na base dos ramos.

Quanto à densidade de vasos, observou-se, no ápice dos ramos, a maior densidade em comparação com as posições mediana e basal do ramo, mas, sem diferença estatística entre os porta-enxertos. Ocorreu diminuição da densidade, conforme a posição no ramo, ou seja, quanto maior é o crescimento secundário do xilema, menor é a densidade de vasos, em razão do crescimento de outras estruturas de sustentação, como fibras e raios parenquimáticos, que também formam o tecido xilemático.

Os porta-enxertos apresentaram diferenças quanto à distribuição e frequência dos elementos de vaso, de acordo com diferentes classes de diâmetros, em cortes transversais realizados na base do ramo (Figura 4). Para os porta-enxertos SO4 e Paulsen 1103, observou-se a predominância de vasos das classes de 40 a $50 \mu \mathrm{m}$ de diâmetro, enquanto no
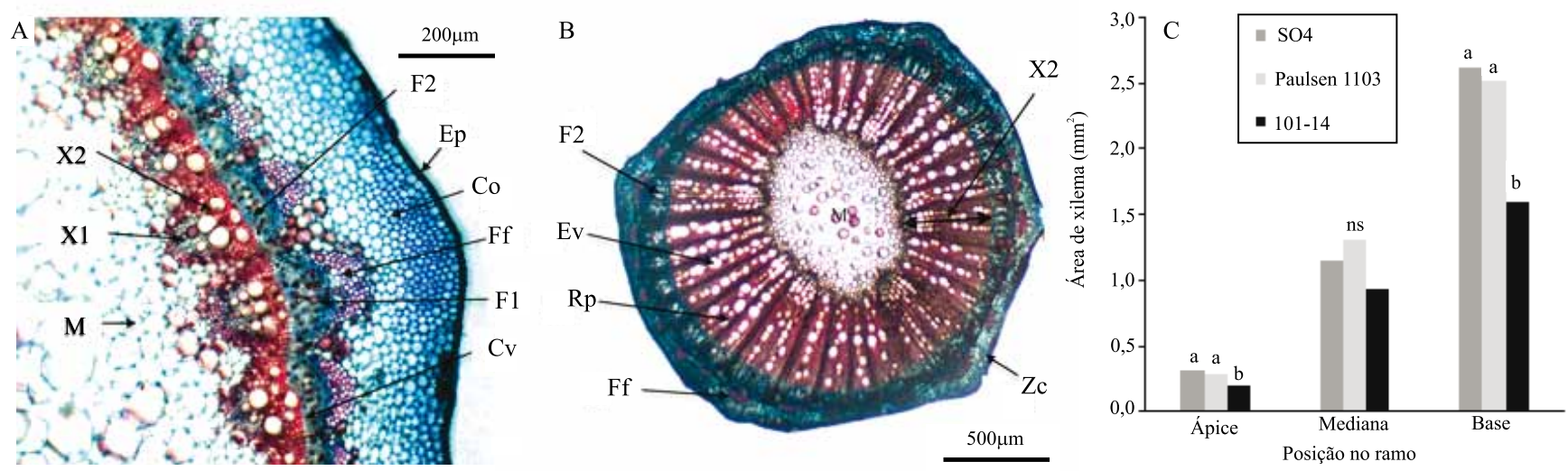

Figura 1. Fotomicrografia da seção transversal na porção apical (A) e mediana (B) dos ramos, em mudas de videira (Vitis sp.). Estrutura do sistema vascular: medula (M), xilema primário (X1), xilema secundário (X2), elementos de vaso (Ev), raios parenquimáticos $(\mathrm{Rp})$, câmbio vascular $(\mathrm{Cv})$, floema primário $(\mathrm{F} 1)$ e secundário $(\mathrm{F} 2)$, fibras do floema (Ff), epiderme (Ep), colênquima $(\mathrm{Co})$ e zona cortical $(\mathrm{Zc})$. Área de xilema $(\mathrm{C})$ em relação à posição no ramo, em diferentes genótipos de porta enxertos de videira (SO4, Paulsen 1103 e MGT 101-14), após 160 dias de crescimento. Letras iguais, para a mesma porção

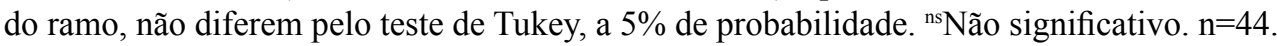


porta-enxerto MGT 101-14 houve predominância de vasos das classes de 20 a 30 e 30 a $40 \mu \mathrm{m}$. SO4 e o Paulsen 1103 apresentaram, também, vasos com diâmetros superiores a $80 \mu \mathrm{m}$, tendo-se observado diâmetros de até $100 \mu \mathrm{m}$ para o SO4, e de até $110 \mu \mathrm{m}$ para o Paulsen 1103. Estes resultados ocorreram em razão da diferença de crescimento vegetativo entre os porta-enxertos, ou seja, houve alteração do padrão de distribuição dos vasos, por meio da modificação da taxa de diferenciação celular que ocorre via câmbio vascular, que é o tecido responsável pelo crescimento secundário, no sentido radial do ramo (Lucas et al.,
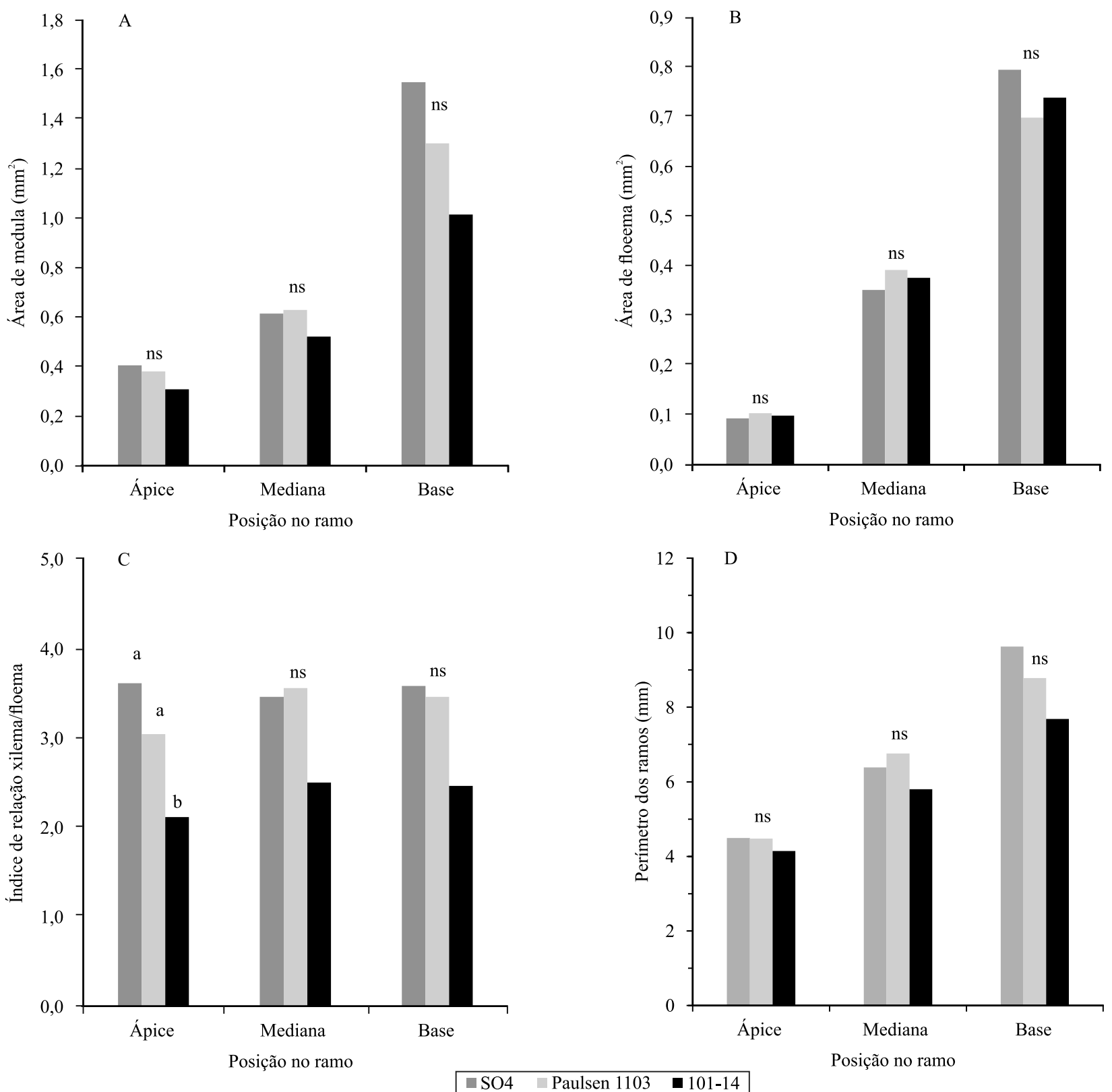

Figura 2. Área de medula (A), floema (B), índice de relação da área xilema/floema (C) e perímetro (D), em relação à posição do ápice, da mediana e da base dos ramos, dos porta-enxertos SO4, Paulsen 1103 e MGT 101-14 de videira (Vitis sp.), após 160 dias de crescimento. Letras iguais, para a mesma posição no ramo, não diferem pelo teste de Tukey, a 5\% de probabilidade. ${ }^{\text {ns }}$ ão significativo. $\mathrm{n}=44$. 
2013), e que pode afetar o padrão de vascularização. Porta-enxertos com menor vigor, como o MGT 101-14, apresentam menor área foliar, menor demanda por evapotranspiração e maior resistência hidráulica para o fluxo de seiva, decorrente da formação de vasos com menor diâmetro. Portanto, verificou-se uma relação direta entre a frequência de vasos de maior diâmetro e os porta-enxertos com maior crescimento vegetativo e, consequentemente, maior vigor. Porta-enxertos mais vigorosos, como o SO4 e o Paulsen 1103, apresentaram maior frequência de vasos (40 e 38\%, respectivamente), com maior
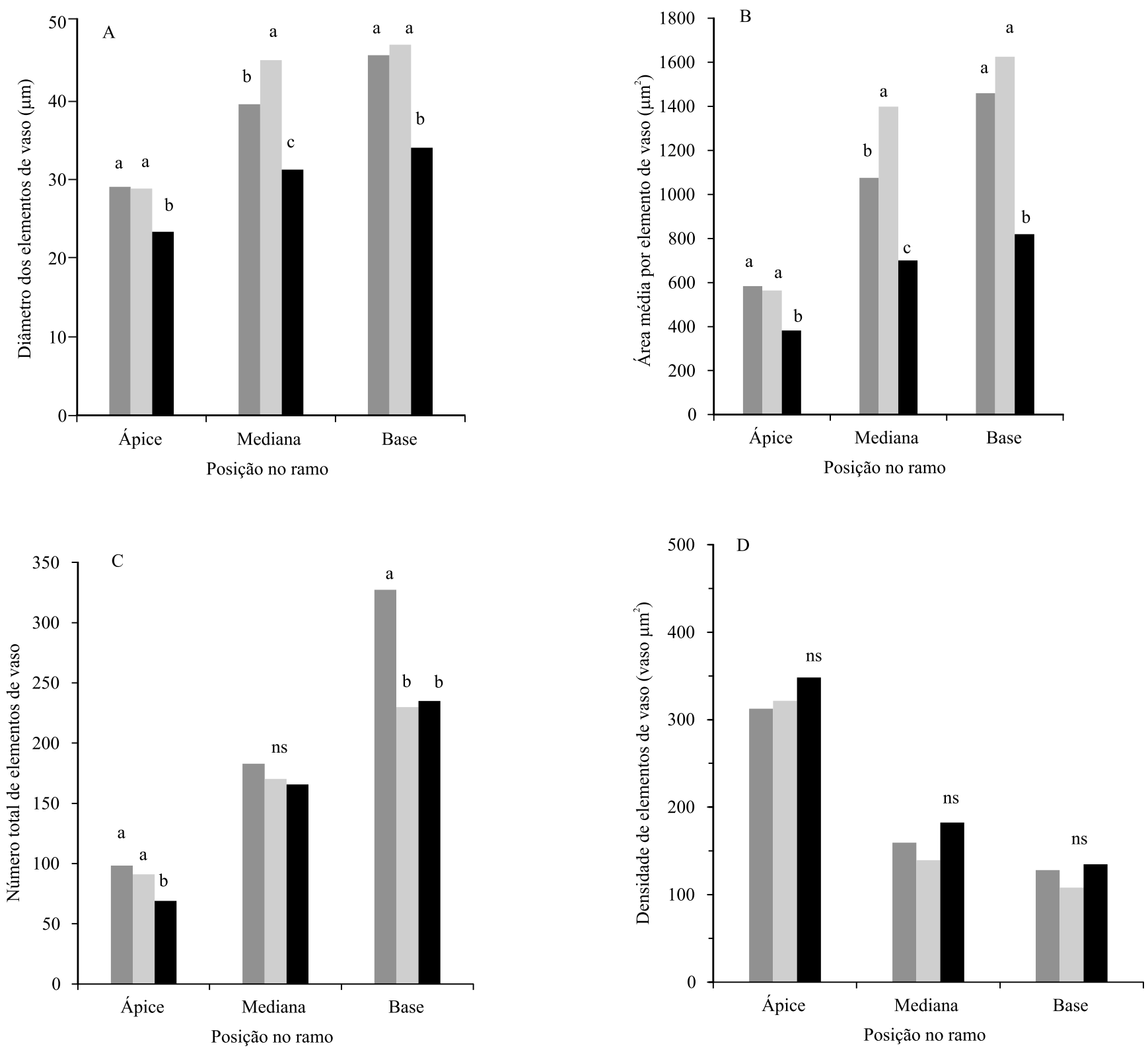

$\square$ SO4 $\square$ Paulsen $1103 \quad \square$ MGT 101-14

Figura 3. Diâmetro (A), área dos elementos de vaso (B), número total (C) e densidade de elementos de vaso (D) no xilema, em relação à posição do ápice, da mediana e da base dos ramos, dos porta-enxertos SO4, Paulsen 1103 e MGT 101-14 de videira (Vitis sp.), após 160 dias de crescimento. Letras iguais, para a mesma porção do ramo, não diferem entre si, pelo teste de Tukey, a 5\% de probabilidade. ns Não significativo. $n=44$. 
diâmetro (acima de $50 \mu \mathrm{m}$ ) do que os porta-enxertos de menor vigor, como o MGT 101-14 que, menos vigoroso, apresentou maior frequência de vasos com diâmetros inferiores a $40 \mu \mathrm{m}$ e diâmetro máximo de 70 a $80 \mu \mathrm{m}$.

Em geral, as alterações anatômicas também foram verificadas em diferentes porções dos ramos, em virtude do crescimento secundário. No mesmo porta-enxerto, observou-se que o padrão de vascularização foi alterado entre o ápice, a porção mediana e a base dos ramos. A maior parte das variáveis apresentou valores menores no ápice, e maiores na base, como a área de xilema, floema, diâmetro médio dos vasos e número total de vasos (Figura 3), exceto a densidade de vasos, que apresentou valor maior no ápice do que na base. Isso pode ser explicado pelo fato de que a densidade depende do número de vasos por unidade de área e que, no ápice, são formados mais vasos em relação a área total de xilema, enquanto, na base dos ramos, embora o número total de vasos e a área de xilema sejam maiores em número absoluto, outras estruturas de sustentação, como as fibras e os raios parenquimáticos, também são formadas em maior proporção. Com estes resultados, salienta-se a importância de conexões entre os elementos de vaso, transporte lateral e vias alternativas para o transporte de água, uma vez que a estrutura do xilema apresenta-se diferentemente entre as zonas do ápice, mediana e base dos ramos. Conforme também apontado por Halis et al. (2012), o fluxo lateral de água e as conexões entre os vasos representam papel essencial no fluxo de seiva.

Os porta-enxertos avaliados apresentaram características diferenciadas quanto à formação do xilema e dos elementos de vaso, com possíveis implicações sobre processos fisiológicas na planta, como a resistência hidráulica ao fluxo de seiva. Estas características podem ser utilizadas como critérios para a escolha dos porta-enxertos. Conforme apontado por Wu et al. (2011), o transporte de água na planta também depende das características anatômicas. Em cerejeiras, a ocorrência de vasos de menor diâmetro e menor número nos tecidos do xilema, no ponto de enxertia, pode resultar em maior resistência hidráulica, o que leva à redução do vigor na brotação (Olmstead et al., 2006). O MGT 101-14 apresentou vasos de menor diâmetro (Figura 3), o que pode estar relacionado à maior resistência hidráulica, com relação direta com o menor vigor vegetativo. Do mesmo modo, raízes com vasos de maior diâmetro no xilema apresentam maior condutividade hidráulica (Gonçalves et al., 2007; Tombesi et al., 2010), o que pode apresentar relação com os resultados dos porta-enxertos Paulsen 1103 e $\mathrm{SO} 4$, que apresentaram vasos com maior diâmetro.
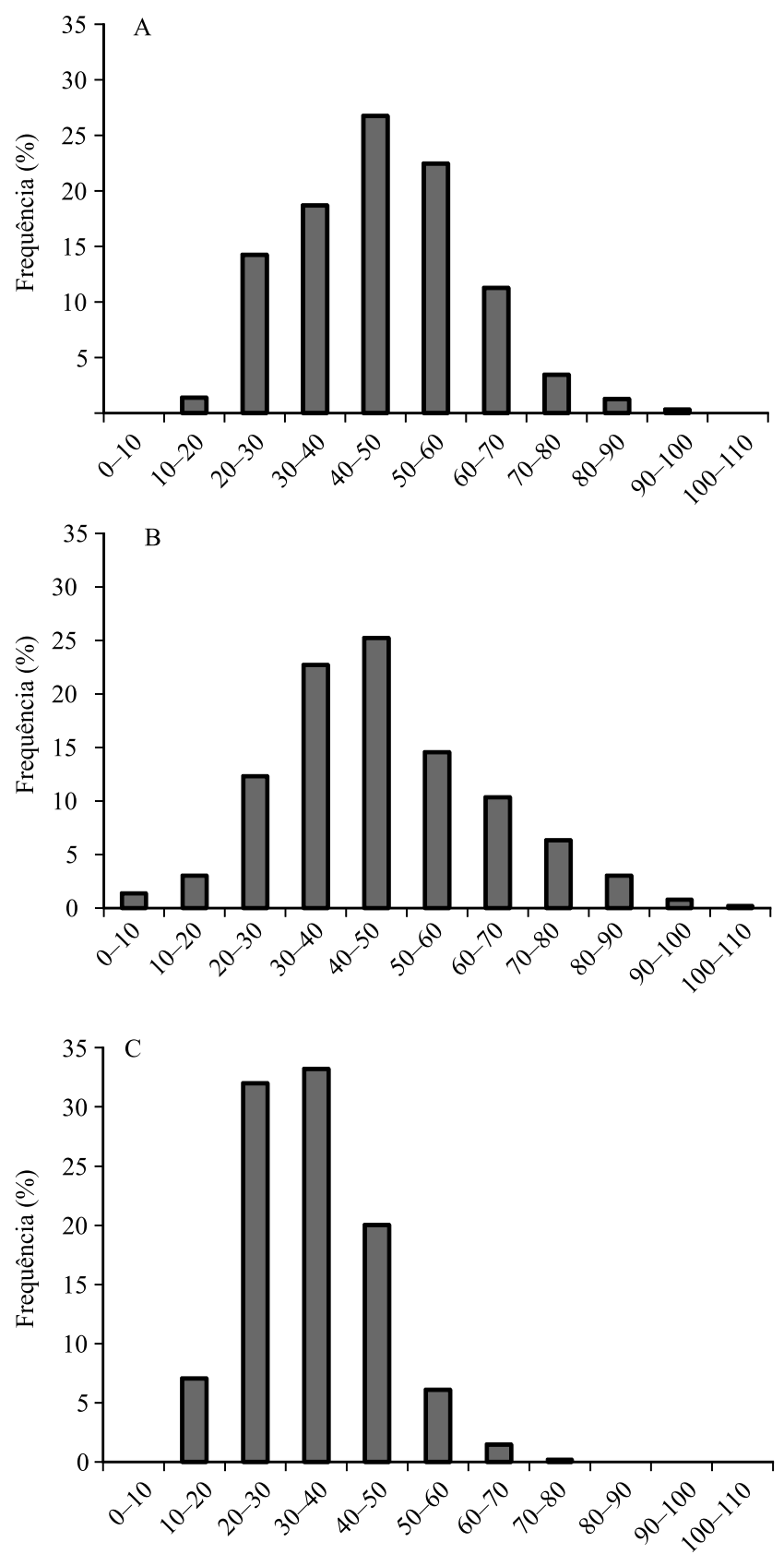

Classes de diâmetro dos elementos de vaso $(\mu \mathrm{m})$

Figura 4. Frequência dos elementos de vaso no tecido xilemático, de acordo com diferentes classes de diâmetros, em cortes transversais realizados na base dos ramos (2. ${ }^{\circ}$ entrenó) dos porta-enxertos de videira (Vitis sp.) $\mathrm{SO} 4$ (A), Paulsen 1103 (B) e MGT 101-14 (C). 
Além disso, em virtude de influências do ambiente, a formação de vasos menores também pode influenciar a diminuição do embolismo ou cavitação (Brodersen et al., 2010), como em regiões com períodos de seca. A falha hidráulica induzida por embolia do xilema é um dos principais mecanismos que ocasiona a morte das plantas durante a seca (Choat et al., 2016). Em razão destes diferentes processos fisiológicos, o transporte de água e nutrientes à longa distância, das raízes até as folhas, é dependente da manutenção da funcionalidade do xilema (Knipfer et al., 2015), em que o padrão de vascularização dos porta-enxertos é fator importante para o fluxo de água no sistema solo-planta-atmosfera. Algumas espécies de videira apresentam diferentes mecanismos de manutenção e reparo da capacidade de transporte do xilema (Knipfer et al., 2015) e, portanto, as características anatômicas dos porta-enxertos também devem ser consideradas neste processo.

As alterações do sistema vascular ocorrem de acordo com as diferenças do crescimento vegetativo, e também são alterados do ápice para a base dos ramos, em que os porta-enxertos Paulsen 1103 e SO4 apresentaram maior área de xilema e maior diâmetro dos vasos do que o MGT 101-14, além de alterações de frequência e distribuição.

Em trabalhos futuros, as interações com as variedades-copa também devem ser avaliadas em plantas adultas, pois estas características anatômicas diferenciadas dos porta-enxertos podem estar relacionadas às diferenças de vigor (crescimento e desenvolvimento) das variedades-copa, com possíveis implicações fisiológicas decorrentes da interação.

\section{Conclusões}

1. Os porta-enxertos de videira apresentam alterações do padrão de vascularização relativos à área de xilema, diâmetro, número total e frequência dos elementos de vaso.

2. As alterações do padrão de vascularização podem ser utilizadas como critérios para a seleção de porta-enxertos, em razão da influência do sistema vascular sobre os processos fisiológicos.

\section{Agradecimentos}

Ao Conselho Nacional de Desenvolvimento Científico e Tecnológico (CNPq), pelo apoio financeiro.

\section{Referências}

ALONI, B.; COHEN, R.; KARNI, L.; AKTAS, H.; EDELSTEIN, M. Hormonal signaling in rootstock-scion interactions. Scientia Horticulturae, v.127, p.119-126, 2010. DOI: 10.1016/j. scienta.2010.09.003.

ALSINA, M.M.; SMART, D.R.; BAUERLE, T.; HERRALDE, F. de; BIEL, C.; STOCKERT, C.; NEGRON, C.; SAVE, R. Seasonal changes of whole root system conductance by a drought-tolerant grape root system. Journal of Experimental Botany, v.62, p.99-109, 2011. DOI: $10.1093 /$ jxb/erq247.

BRODERSEN, C.R.; MCELRONE, A.J.; CHOAT, B.; MATTHEWS, M.A.; SHACKEL, K.A. The dynamics of embolism repair in xylem: in vivo visualizations using high-resolution computed tomography. Plant Physiology, v.154, p.1088-1095, 2010. DOI: $10.1104 /$ pp.110.162396.

CHATELET, D.S.; WISTROM, C.M.; PURCELL, A.H.; ROST, T.L.; MATTHEWS, M.A. Xylem structure of four grape varieties and 12 alternative hosts to the xylem-limited bacterium Xylella fastidious. Annals of Botany, v.108, p.73-85, 2011. DOI: 10.1093/ aob/mer106.

CHOAT,B.;BADEL,E.;BURLETT, R.;DELZON, S.;COCHARD, H.; JANSEN, S. Noninvasive measurement of vulnerability to drought-induced embolism by x-ray microtomography. Plant Physiology, v.170, p.273-282, 2016. DOI: 10.1104/pp.15.00732.

CHOAT, B.; GAMBETTA, G.A.; SHACKEL, K.A.; MATTHEWS, M.A. Vascular function in grape berries across development and its relevance to apparent hydraulic isolation. Plant Physiology, v.151, p.1677-1687, 2009. DOI: 10.1104/pp.109.143172.

COHEN, S.; NAOR, A.; BENNINK, J.; GRAVA, A.; TYREE, $\mathrm{M}$. Hydraulic resistance components of mature apple trees on rootstocks of different vigours. Journal of Experimental Botany, v.58, p.4213-4224, 2007. DOI: 10.1093/jxb/erm281.

GERLACH, D. Botanische Mikrotechnik: Eine Einführung. Stuttgart: Georg Thieme Verlag, 1977. 311p.

GONÇALVES, B.; CORREIA C.M.; SILVA, A.P.; BACELAR, E.A.; SANTOS, A.; FERREIRA, H.; MOUTINHO-PEREIRA, J.M. Variation in xylem structure and function in roots and stems of scion-rootstock combinations of sweet cherry tree (Prunus avium L.).Trees, v.21, p.121-130, 2007. DOI: 10.1007/ s00468-006-0102-2.

HALIS, Y.; DJEHICHI, S.; SENOUSSI, M.M. Vessel development and the importance of lateral flow in water transport within developing bundles of current-year shoots of grapevine (Vitis vinifera L.). Trees, v.26, p.705-714, 2012. DOI: 10.1007/ s00468-011-0637-8.

JUNG, J.H.; PARK, C.M. Vascular development in plants: specification of xylem and phloem tissues. Journal of Plant Biology, v.50, p.301-305, 2007. DOI: 10.1007/BF03030658.

KELLER, M.; MILLS, L.J.; HARBERTSON, J.F. Rootstock effects on deficit-irrigated winegrapes in a dry climate: vigor, yield formation, and fruit ripening. American Journal of Enology and Viticulture, v.63, p.29-39, 2012. DOI: 10.5344/ajev.2011.11078. 
KNIPFER, T.; EUSTIS, A.; BRODERSEN, C.; WALKER, A.M.; MCELRONE, A.J. Grapevine species from varied native habitats exhibit differences in embolism formation/repair associated with leaf gas exchange and root pressure. Plant, Cell and Environment, v.38, p.1503-1513, 2015. DOI: 10.1111/pce.12497.

KOUNDOURAS, S.; TSIALTAS, I.T.; ZIOZIOU, E.; NIKOLAOU, $\mathrm{N}$. Rootstock effects on the adaptive strategies of grapevine (Vitis vinifera L. cv. Cabernet-Sauvignon) under contrasting water status: leaf physiological and structural responses. Agriculture, Ecosystems and Environment, v.128, p.86-96, 2008. DOI: 10.1016/j.agee.2008.05.006.

LOVISOLO, C.; SCHUBERT, A.; SORCE, C. Are xylem radial development and hydraulic conductivity in downwardly-growing grapevine shoots influenced by perturbed auxin metabolism? New Phytologist, v.156, p.65-74, 2002. DOI: 10.1046/j.1469-8137.200 2.00492.x.

LUCAS, W.J.; GROOVER, A.; LICHTENBERGER, R.; FURUTA, K.; YADAV, S.R.; HELARIUTTA, Y.; XIN-QIANG, H.; FUKUDA, H.; KANG, J.; BRADY, S.M.; PATRICK, J.W.; SPERRY, J.; YOSHIDA, A.; LÓPEZ-MILLÁN, A.-F.; GRUSAK, M.A.; KACHROO, P. The plant vascular system: evolution, development and functions. Journal of Integrative Plant Biology, v.55, p.294-388, 2013. DOI: 10.1111/jipb.12041.

MARTÍNEZ-BALLESTA, M.C.; ALCARAZ-LÓPEZ, C.; MURIES, B.; MOTA-CADENAS, C.; CARVAJAL, M. Physiological aspects of rootstock-scion interactions. Scientia Horticulturae, v.127, p.112-118, 2010. DOI: 10.1016/j. scienta.2010.08.002.

MIELE, A.; RIZZON, L.A.; GIOVANNINI, E. Efeito do porta-enxerto no teor de nutrientes em tecidos da videira 'Cabernet Sauvignon'. Revista Brasileira de Fruticultura, v.31, p.1141-1149, 2009. DOI: 10.1590/S0100-29452009000400031.

O'BRIEN, T.P.; MCCULLY, M.E. The study of plant structure: principles and selected methods. Melbourne: Termarcarphi, 1981. $345 \mathrm{p}$.

OLMSTEAD, M.A.; LANG, N.S.; EWERS, F.W.; OWENS, S.A. Xylem vessel anatomy of sweet cherries grafted onto dwarfing and nondwarfing rootstocks. Journal of American Society of Horticultural Science, v.131, p.577-585, 2006.

PAVLOUSEK, P. Evaluation of drought tolerance of new grapevine rootstock hybrids. Journal of Environmental Biology, v.32, p.543-549, 2011.
PIRE, R.; PEREIRA, A.; DÍEZ, J.; FERERES, E. Influence of rootstock and irrigation level on water relations of grapevines grown under tropical conditions. Journal of Food, Agriculture and Environment, v.8, p.703-709, 2010.

RODRÍGUEZ-GAMIR, J.; INTRIGLIOLO, D.S.; PRIMO-MILLO, E.; FORNER-GINER, M.A. Relationships between xylem anatomy, root hydraulic conductivity, leaf/root ratio and transpiration in citrus trees on different rootstocks. Physiologia Plantarum, v.139, p.159-169, 2010. DOI: 10.1111/j.1399-3054.2010.01351.x.

SANTAROSA, E.; SOUZA, P.V.D. de; MARIATH, J.E. de A.; LOUROSA, G.V. Physiological interaction between rootstock-scion: effects on xylem vessels in Cabernet Sauvignon and Merlot grapevines. American Journal of Enology and Viticulture, v.67, p.65-76, 2016. DOI: 10.5344/ajev.2015.15003.

SCHNEIDER, C.A.; RASBAND, W.S.; ELICEIRI, K.W. NIH Image to ImageJ: 25 years of image analysis. Nature Methods, v.9, p.671-675, 2012. DOI: 10.1038/nmeth.2089.

SOLARI, L.I.; DEJONG, T.M. The effect of root pressurization on water relations, shoot growth, and leaf gas exchanges of peach (Prunus persica) trees on rootstocks with differing growth potential and hydraulic conductance. Journal of Experimental Botany, v.57, p.1981-1989, 2006. DOI: 10.1093/jxb/erj145.

SOLARI, L.I.; JOHNSON, S.; DEJONG, T.M. Hydraulic conductance characteristics of peach (Prunus persica) trees on different rootstocks are related to biomass production and distribution. Tree Physiology, v.26, p.1343-1350, 2006. DOI: 10.1093/treephys/26.10.1343.

THORNE, E.T.; YOUNG, B.M.; YOUNG, G.M.; STEVENSON, J.F.; LABAVITCH, J.M.; MATTHEWS, M.A.; ROST, T.L. The structure of xylem vessels in grapevine (Vitaceae) and a possible passive mechanism for the systemic spread of bacterial disease. American Journal of Botany, v.93, p.497-504, 2006. DOI: 10.3732/ajb.93.4.497.

TOMBESI, S.; JOHNSON, R.S.; DAY, K.R.; DEJONG, T.M. Relationships between xylem vessel characteristics, calculated axial hydraulic conductance and size-controlling capacity of peach rootstocks. Annals of Botany, v.105, p.327-331, 2010. DOI: 10.1093/aob/mcp281.

WU, H.; JAEGER, M.; WANG, M.; LI, B.; ZHANG, B.G. Three-dimensional distribution of vessels, passage cells and lateral roots along the root axis of winter wheat (Triticum aestivum). Annals of Botany, v.107, p.843-853, 2011. DOI: 10.1093/aob/ mer005.

Recebido em 29 de maio de 2015 e aprovado em 11 de março de 2016 


\section{ERRATA}

No artigo "Alterações anatômicas do sistema vascular em porta-enxertos de videira", publicado na Pesquisa Agropecuária Brasileira, v.51, n.4, p.320-329, 2016, DOI: 10.1590/S0100204X2016000400004, na página 326, na Figura 3 D, no eixo y, onde se lê:

"Densidade de elementos de vaso (vaso $\left.\mu \mathrm{m}^{2}\right)$ ",

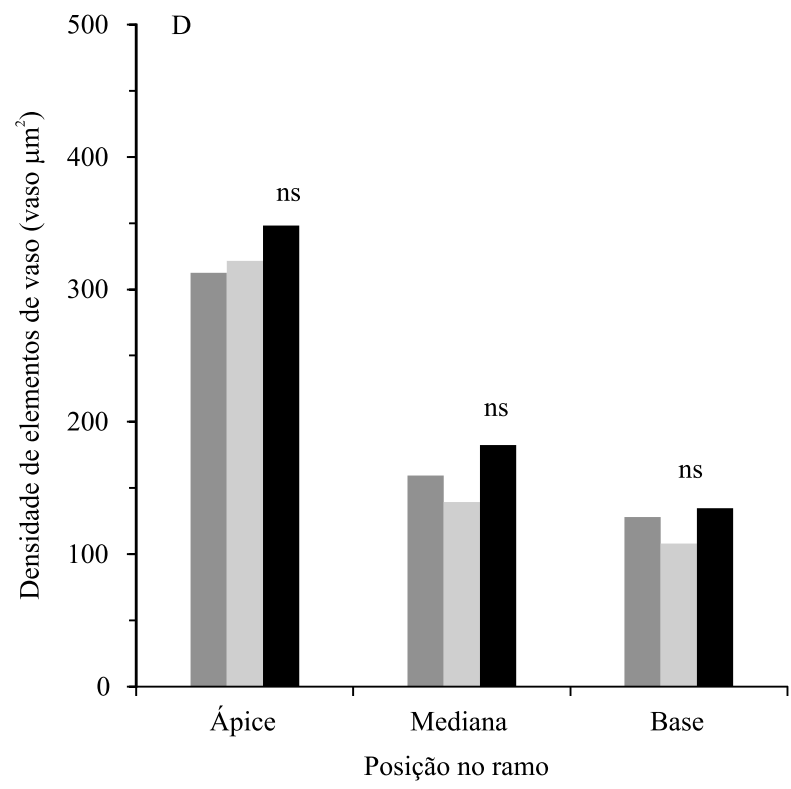

- SO4 Paulsen $1103 \quad$ MGT 101-14

leia-se:

"Densidade de elementos de vaso (vasos $\left.\mathrm{mm}^{-2}\right)$ ".

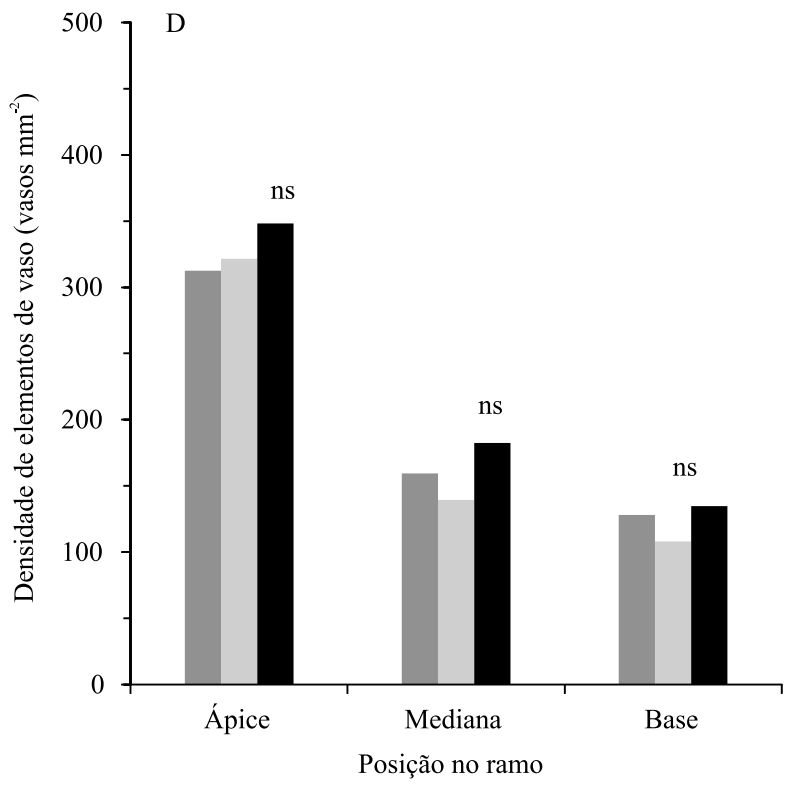

$\square$ SO4 $\square$ Paulsen $1103 \quad \square$ MGT 101-14 